\title{
Recovery of Renewable Aromatic and Aliphatic HydrocarbonResources from Microwave Pyrolysis/Co-Pyrolysis of Agro-residues and Plastics Wastes
}

Dadi V. Suriapparao ${ }^{\mathrm{a}, *}$, Attada Yerrayya ${ }^{\mathrm{b}}$, Garlapati Nagababuc, Ramesh K. Guduru ${ }^{\mathrm{c}}$, Tanneru Hemanth Kumard

aDepartment of Chemical Engineering, PanditDeendayal Petroleum University, Gandhinagar-382007, India

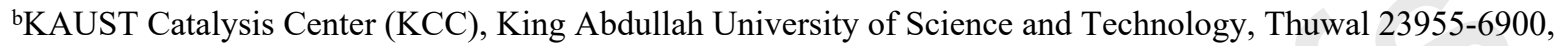
Saudi Arabia

'Department of Mechanical Engineering, PanditDeendayal Petroleum University, Gandhinagar-382007, India

${ }^{\mathrm{d} D e p a r t m e n t}$ of Chemical Engineering, Indian Institute of petroleum Energy, Visakhapatnam-530003, India

\begin{abstract}
The present study focussed on recovering the valuable carbon resources from agroresidues (wheat straw, rice husk) and waste plastics (polypropylene, polystyrene) using microwave pyrolysis and co-pyrolysis. The main objective of this study is to investigate the effect of the susceptor blending mechanism on the co-pyrolysis product distribution. Graphite was mixed with feedstock in a new approach to achieving homogeneity, and microwave power of $600 \mathrm{~W}$ was used. The average heating rate $\left(52-67\left({ }^{\circ} \mathrm{C} / \mathrm{min}\right)\right)$, microwave energy required (2267-2936 (J/g)), heat energy utilized (1410-1444 (J/g)), and conductive heat losses (85-110 $(\mathrm{J} / \mathrm{g}))$ were analyzed. The selectivity of cyclic alkanes and alkenes $(65.5 \%)$ was found to be high in polypropylene pyrolysis oil. Polystyrene pyrolysis oil predominantly contained cyclooctatetraene (61\%) compound. Bio-oil obtained from wheat straw predominantly contained aromatic hydrocarbons (85\%), whereas rice husk oil also contains high selectivity aromatic hydrocarbons (37.8\%) along with aliphatic hydrocarbons (54.9\%). The co-pyrolysis oils has high selectivity of aromatics.
\end{abstract}

*Corresponding author. E-mail address: suryadadi165@gmail.com (Dadi V. Suriapparao) 
Keywords: Wheat Straw; Rice Husk; Expanded Polystyrene; Waste polypropylene; Microwave Co-Pyrolysis

\section{Introduction}

There is a need to adopt new and renewable sources for meeting the requirements of energy, chemicals, and materials. In this concern, biomass is the only renewable source that can replace fossil sources (Coal, Petroleum, and Natural gas) for the production of renewable carbon fuels and chemicals (Naqvi et al., 2019). Solid waste management in India is the need of the day to impart value addition to both rural and urban solid wastes. The renewable energy program in India is focused on the utilization of bioenergy. Rural India produces around 686 Million Tons of crop residual biomass waste per annum. Rice, sugarcane, wheat, and cotton crops are the major contributors to this bioenergy reserve (Hiloidhari et al., 2014). On the other side, urban India contributes to the accumulation of around 1.35 lakh Tons per day of municipal solid waste. Out of which, 15000 Tons per day plastic waste is also present, and only a fraction of it is recycled while leaving the rest uncollected (Alam et al., 2020). Therefore, tapping these resources is vital for sustainable development as well as and the mitigation of pollution issues in the nation.

In the domain of solid waste management for resource recovery, pyrolysis is one of the paramount thermo-chemical technology to valorize biomass and waste plastics (Anex et al., 2010). A high yield of solid feedstock conversion into liquefied chemicals and fuels is achievable through the pyrolysis technique, where high heating rate and low vapor residence play a crucial role. The oils from the biomass pyrolysis essentially contain valuable oxygenated chemicals, which include phenols, acids, esters, aldehydes, ketones, and furan derivatives. Due to the presence of oxygenates, the oil contains high oxygen content, low calorific value, high acidity, high viscosity, and becomes highly unstable (Abnisa and Wan Daud, 2014). On the other 
side, plastic pyrolysis oil is rich in aliphatic and aromatic hydrocarbons, which has a huge potential in the petrochemical industry (Park et al., 2019). The up-gradation of oils obtained from biomass and plastic pyrolysis is essential to enhance the storage and transportation properties.

Among different oil up-gradation techniques, the processing of oxygen-rich biomass with hydrocarbon-rich plastics is the best approach via the co-pyrolysis technique (Navarro et al., 2018). It is also a very beneficial effective waste management system compared to pyrolysis alone (Uzoejinwa et al., 2018). Co-pyrolysis is also beneficial for the production of chemical feedstocks and value-added products on the bulk scale (Kumagai et al., 2020). Several studies were reported on the co-pyrolysis of biomass and plastics mixtures. In the almond shell with high-density polyethylene, the co-pyrolysis oil had higher carbon and hydrogen contents with lower oxygen content compared to biomass oil (Önal et al., 2014). Pinewood chips co-pyrolysis with different plastics (tyre, polylactic acid, polystyrene (PS), polyethylene terephthalate (PET), polypropylene (PP), high-density polyethylene (HDPE)) observed synergetic interactions due to difference in calculated and experimental values (Navarro et al., 2018). In walnut shells and peach stones with PET, PS, polyvinyl chloride (PVC) co-pyrolysis, the addition of polymers to the biomass affected the product yields. The chemical structure of co-pyrolysis tar modified significantly with high yield compared to biomass pyrolysis (Özsin and Pütün, 2018). The synergetic effect promoted the aromatic hydrocarbons yield and reduced the carbon chain length in the co-pyrolysis of pinewood with low-density polyethylene (LDPE) (Zheng et al., 2018). The acid-treated corn stover co-pyrolysis with polyethylene (PE) synergistically reduced the char yield and increased the yield and quality of co-pyrolysis oil fraction (Xue and Bai, 2018).In the co-pyrolysis of eucalyptus wood, and rice straw with PE showed a positive effect on biomass decomposition with the formation of the new substances (Fan et al., 2019). The co-pyrolysis 
synergy predominantly reduced the apparent activation energy requirement compared to sole biomass pyrolysis (Chen et al., 2018). The synergy in co-pyrolysis also showed the variation in the calorific value of oil, the obtained oil can be blended with conventional fuels (Chen et al., 2019). The synergy between the biomass and plastics were observed in product yields and composition. The synergistic interactions among the evolved biomass and plastic pyrolysates could enhance the hydrocarbon yield with reduced char formation (Johansson et al., 2018). The increase in plastic ratio in the feedstock also resulted in a decrease of activation energy (Oyedun et al., 2014). The initiation, secondary radical formation, termination by disproportionation, and recombination of radical reactions are responsible for a positive synergistic effect in co-pyrolysis (Önal et al., 2014).However, both pyrolysis and co-pyrolysis are energy-intensive processes and require $1.5 \mathrm{MJ} / \mathrm{kg}$ of biomass processed (Daugaard and Brown, 2003). In this aspect, efficient and non-conventional conversion technologies are much needed to enhance the heat and mass transport during the pyrolysis processes.

In this respective, microwave-assisted pyrolysis is one of the advanced technologies for the conversion of terrestrial biomass (Dai et al., 2020; Parvez et al., 2020; Zhou et al., 2020), algae (Beneroso et al., 2013; Ferrera-Lorenzo et al., 2014; Hu et al., 2013), plastics (Song et al., 2017; Suriapparao and Vinu, 2015; Undri et al., 2014), heterogeneous solid wastes (Beneroso et al., 2014; Xie et al., 2014; Yu et al., 2014) into value-added products. The microwave power, pyrolysis temperature, heating rate, feedstock nature and quantity, and the type of susceptor play a key role in the control of pyrolysis. Most importantly, the fast and flash pyrolysis product yields can be obtained at very low bulk heating rates of $10^{\circ} \mathrm{C} / \mathrm{min}$ to $80^{\circ} \mathrm{C} / \mathrm{min}$ due to inherent plasma-enhanced cracking reactions (Suriapparao et al., 2020; Suriapparao and Vinu, 2015). Carbonaceous susceptors viz. graphite, activated carbon, and pyrolysis char is used as a 
susceptor due to their high microwave absorption properties (Bhattacharya and Basak, 2017). Nevertheless, to the best of our knowledge, very little research has been reported on the microwave-assisted co-pyrolysis of biomass and plastics (Bu et al., 2019, 2018; Suriapparao et al., 2020, 2018). Most importantly, the study on agro-residual biomass with waste plastics is highly needed to tap valuable chemicals and materials.

Hence, the current research work is focused on the microwave co-pyrolysis of agroresidues with waste plastics. Wheat straw and rice husk were chosen as biomass feedstocks due to their high proportion in agro-residues (Hiloidhari et al., 2014). Expanded polystyrene and polypropylene plastic bottle waste were used as plastic precursors. The uniqueness of this study is, graphite susceptor mixing homogeneously within the molten waste plastic feedstock and conducted the pyrolysis. This new blending approach would result in more uniform heat and mass transfer during the microwave susceptor interactions. The temperature and time data were collected for each experiment to investigate the pyrolysis time, type of pyrolysis, and energy requirement comparison. The average heating rates, energy requirement, product yields, product composition, and hydrocarbon yields were thoroughly investigated. The physicochemical properties of the oil fraction were thoroughly studied to understand its storage stability, fluid flow properties, and energy density. The energy requirement in pyrolysis and co-pyrolysis was evaluated from the temperature, pyrolysis time, and mass of feedstock data. To this end, this work would help in a better understanding of the resource recovery from the co-pyrolysis of biomass and plastic mixtures.

\section{Materials and Methods}

\subsection{Raw Materials}


The raw materials viz. Graphite, Wheat Straw (WS), Rice Husk (RH), Expanded Polystyrene (EPS) (it is widely known as thermocol), and Waste Polypropylene (WPP) bottles were used in this study. Graphite powder was obtained from S.D. Fine ChemPvt. Ltd., India, and they were subjected to size reduction and sieving to an average particle size of $100 \mu \mathrm{m}$. Wheat straw was obtained from a local farmer in the Gandhinagar area, Gujarat, India; rice husk was brought from a farmer belongs to Kothapalem village of Visakhapatnam district, Andhrapradesh, India. WS and RH were also subjected to crushing, grinding, and sieving operation to obtain an average particle size of $\sim 200 \mu \mathrm{m}$.EPS and WPP were collected from a waste plastics segregation point located in Gandhinagar city. Both the EPS and WPP were washed with running tap water to remove the dirt and other contaminants. It was cut into square pieces of $1 \mathrm{~cm} \times 1 \mathrm{~cm}$ by laboratory hand cutter. Then, all the samples were dried at a temperature of $150^{\circ} \mathrm{C}$ to remove the physically bound moisture using the research-grade microwave reactor (Ragatech Industrial/Scientific Microwave Systems, Pune, India). The samples were stored in an airtight zip-lock cover for further utilization to its characterization, feedstock preparation, and for pyrolysis and co-pyrolysis experiments.

\subsection{Characterization of Raw Materials}

The samples were characterized for thermal stability, proximate, elemental, and heating value and porosity analyses. The thermogravimetric analyzer (TGA, Perkin Elmer STA 600) was used to determine the thermal stability and the proximate data (moisture, volatile matter, fixed carbon, and ash contents). The elemental analyzer (ElementarVario EL III) was used to quantify the elemental $\mathrm{C}, \mathrm{H}, \mathrm{N}$, and $\mathrm{S}$ in the total composition. The heating value was analyzed using a bomb calorimeter (Model: IKA C2000). The internal surface area was measured usingMicromeritics ASAP 2020 porosimeter. 


\subsection{Microwave-Assisted Pyrolysis/Co-Pyrolysis ExperimentalSetup}

The research-grade microwave reactor (Model: RG34L1500, RAGA'S Scientific Microwave Systems, Ragatech, Pune, India) was used for conducting the pyrolysis and copyrolysis experiments. It has a microwave power delivery range of $300 \mathrm{~W}$ to $1500 \mathrm{~W}$ with a constant frequency of $2.45 \mathrm{GHz}$.An inbuilt temperature sensor with a controller was provided along with the digital monitoring system. Provision was arranged for connecting the quartz reactor with an external vapor condensation system. Three circular openings on the top and one at the side of the oven cavity was provided. A microwave compatible K-type thermocouple was used to measure the sample bed temperature. A $500 \mathrm{~mL}$ flat-bottom three-neck flask made of quartz was used as a reactor. The conductive heat losses through the sample bed and quartz flask were minimized by wrapping with low thermal conductivity quartz wool insulation. The vapors coming from the quartz reactor outlet were condensed using a multi-stage water-cooled glass condenser. Pyrolysis oil was collected in the oil collection flasks. The detailed schematic of the experimental setup is depicted in Fig $\mathbf{1}$.

\subsection{Feedstock Preparation and Experimental Procedure}

The raw materials feedstock stored in the zip lock covers were used to conduct pyrolysis and co-pyrolysis experiments. In the first step, individual biomass pyrolysis of WS and RH was conducted by taking $50 \mathrm{~g}$ of biomass mixed with $50 \mathrm{~g}$ of graphite susceptor. Then, in the second step, individual plastic pyrolysis (EPS, WPP) was conducted by taking $50 \mathrm{~g}$ of plastic feedstock. The plastic feedstock was melted and blended with $50 \mathrm{~g}$ of graphite susceptor particles. The melting was performed by placing the plastic in the glass beaker and heated till it melts and susceptor particles were blending with the plastic molten phase with the laboratory stirrer. Then the mixture was cool down to room temperature. Finally, in the third step, the co-pyrolysis of 
biomass and plastics was conducted by mixing at 50\%:50\% (wt./wt.) ratio of biomass and plastic. Hence, $25 \mathrm{~g}$ of biomass with $25 \mathrm{~g}$ of plastics with four different combinations (WS:WPP, WS:EPS, RH:WPP, RH:EPS) was used in all the experiments. The equal ratio was found to be optimum for the high yield and conversion with enough hydrogen transfer from the plastic feedstock (Patil et al., 2018; Suriapparao et al., 2018; Xue and Bai, 2018). The co-pyrolysis feed blend was melted and mixed with $50 \mathrm{~g}$ of graphite susceptor. The mixture was stirred with a laboratory stirrer to achieve a uniform distribution of graphite particles. In all the experiments, the feed mixture was placed in a quartz flask, and the entire system was purged with $\mathrm{N}_{2}$ gas at a flow rate of $50 \mathrm{~mL} / \mathrm{min}$ for $30 \mathrm{~min}$ to avoid the atmospheric oxygen contamination. A total of eight experiments were performed at a constant microwave power of $600 \mathrm{~W}$, and pyrolysis was conducted up to $450^{\circ} \mathrm{C}$, where the feedstock conversion was completed, and no further mass loss was observed. At the end of each experiment, the quantity of oil and char was measured gravimetrically, and the quantity of the gas was obtained by mass balance. All the eight experiments were repeated three times, and the standard deviation in the yields of char, oil, and gas was within $1 \%$.

We have followed a new concept in the susceptor mixing with the feedstock, as shown in Fig 2. In the biomass pyrolysis, initially, biomass and graphite were soaked in the alcohol and well mixed with the laboratory stirrer to achieve a uniform distribution of graphite and biomass particles. In the plastic pyrolysis, the plastic feedstock was melted down and graphite particles were added by thoroughly mixing with the stirrer. In the co-pyrolysis experiments, the plastic feedstock was melted down, followed by the addition of biomass and graphite particles. This approach was aimed at achieving uniform heat distribution during the pyrolysis and co-pyrolysis experiments due to the homogenous dispersion of graphite particles. 


\subsection{Energy Utilization Analysis}

There have been no reports so far on the energy utilization for the microwave pyrolysis and co-pyrolysis experiments. Hence, we have done the complete energy analysis including, input microwave energy, sensible heat stored in graphite and quartz flasks, the conductive heat losses, and finally, the heat energy used in the pyrolysis and co-pyrolysis. The microwave energy required was calculated by using equation (1). The sensible heat stored in the susceptor bed, quartz flask was evaluated using the equations (2) and (3). Specific heats of graphite and quartz were calculated using equations (4) and (5). The conductive heat losses through the quartz wool insulation were calculated using the equation (6). The initial temperature was taken as ambient, and the final pyrolysis temperature was taken as $450^{\circ} \mathrm{C}$. The pyrolysis processing time was the time needed to achieve the final pyrolysis temperature.

$$
\begin{aligned}
& M W_{r}=M W_{p} \times t \\
& Q_{G}=m_{G} \times C_{P G} \times d T \\
& Q_{Q}=m_{Q} \times C_{P Q} \times d T \\
& C_{P G}\left(\frac{C a l}{m o l . K}\right)=\left[2.673+0.002671 \times T-\frac{116900}{T^{2}}\right] \\
& C_{P Q}\left(\frac{C a l}{m o l . K}\right)=[10.95+0.0055 \times T] \\
& Q_{c l}=K_{Q} \times A_{Q} \times \frac{d T}{d x}
\end{aligned}
$$

Here, $\mathrm{MW}_{\mathrm{r}}$ - microwave energy required, $\mathrm{MW}_{\mathrm{p}}$-microwave power, $\mathrm{t}$-pyrolysis processing time, $\mathrm{Q}_{\mathrm{G}^{-}}$sensible heat energy stored in the graphite powder, $\mathrm{Q}_{\mathrm{Q}}$ - sensible heat energy stored in the quartz flask, $\mathrm{m}_{\mathrm{G}^{-}}$the mass of graphite powder, $\mathrm{m}_{\mathrm{Q}^{-}}$the mass of quartz flask, $\mathrm{C}_{\mathrm{PG}}$-specific heat of 
graphite, $\mathrm{Cp}_{\mathrm{Q}}$-specific heat of quartz, $\mathrm{K}_{\mathrm{Q}}$-thermal conductivity of quartz wool, $\mathrm{A}_{\mathrm{Q}}$-area of quartz wool insulation, dx-thickness of insulation, and $\mathrm{Q}_{\mathrm{cl}}$ is the conductive heat losses to the oven cavity.

\subsection{Analyses of EndProducts}

Bio-oil, plastic pyrolysis oil, and co-pyrolysis oil samples were initially analyzed for their physicochemical properties, and detailed composition analysis was carried out using Gas Chromatography and Mass Spectrometry technique. Physico-chemical properties, which include, viscosity, density (Stabinger viscometer, SVM 3000, Anton Parr), flash point (AutoFlash-93, Acute Instruments, India), and higher heating value (HHV) (bomb calorimeter, IKA C2000) were analyzed.GC/MS was used for the oil composition analysis (Make: Agilent 7890, 5975C), $0.25 \mu \mathrm{L}$ of diluted sample was injected. The raw oil was diluted using a dichloromethane solvent at a dilution ratio of 100:1 (vol./vol.). Rxi-5Sil MS (30 m length $\times 0.25 \mathrm{~mm}$ i.d. $\times 0.25 \mu \mathrm{m}$ film thickness) column was used for the separation of compounds in the oil fraction. High purity helium gas was used as a carrier at a flow rate of $3.5 \mathrm{~mL} \mathrm{~min}{ }^{-1}$. The GC oven was isothermally held at $75^{\circ} \mathrm{C}$ for $1 \mathrm{~min}$, and then ramped up to $350^{\circ} \mathrm{C}$ at a heating rate of $10^{\circ} \mathrm{C} \mathrm{min}-1$. Finally, it was maintained for $30 \mathrm{~min}$ at this temperature for obtaining a clear spectrum of compounds. The compounds were detected using an MS detector. The MS ion source and detector temperatures were set at $225^{\circ} \mathrm{C}$ and $175^{\circ} \mathrm{C}$, respectively, and the mass range scanned was from 50 to 500 Da. The sample injector temperature was set at $310^{\circ} \mathrm{C}$, and the split ratio was maintained at 50:1. The compounds were identified by comparing the mass spectra with the NIST library, and the compounds having match factor greater than $85 \%$ were considered. The obtained compounds were sub-categorized as aliphatic oxygenates, aromatic oxygenates, aliphatic hydrocarbons, and aromatic hydrocarbons. The carbon number distribution and the yields of carbon, hydrogen, and 
oxygen were calculated using the GC/MS selectivity data. The solid char was analyzed for the elemental, calorific value, and porosimetry analyses.

\section{Results and Discussions}

\subsection{Analysis of Raw Materials}

The proximate, elemental, and heating value analysis of the raw materials is reported in

Table 1. From this analysis, it is evident that the graphite powder is fully built with a carbon (98 wt. \%C) network. It is highly stable and having negligible mass loss (1 wt. \%) when it was exposed to a final temperature of $1000^{\circ} \mathrm{C}$. Hence, the graphite is a suitable carbonaceous susceptor material that would act as a thermal energy generator for the microwave pyrolysis. On the other hand, wheat straw has a high amount of volatile content $(80.7 \mathrm{wt} . \%)$, which can be converted into condensable oil and non-condensable gases in the pyrolysis. Nearly half of the wheat straw mass (50.8 wt.\%) is composed of oxygen element, and hence we can expect production of oxygenated organics. The high amount of oxygen resulted in a low heating value (17.5 MJ/kg). The carbon (42.5 wt.\%) followed by hydrogen (5.5 wt.\%) in the structure can be converted into valuable renewable chemical intermediates. In the rice husk analysis, it was observed that 63 wt. $\%$ of the whole mass was convertible, and it was lesser compared to wheat straw. Most importantly, it contained a high amount of inorganic ash constituents (24.5 wt.\%). The presence of high oxygen content (53 wt.\%) and ash resulted in a low heating value (14.5 $\mathrm{MJ} / \mathrm{kg}$ ). Both the biomasses contained hydrogen (5 wt.\%) and trace amounts of sulphur and nitrogen. The proximate and elemental analysis of wheat straw and rice husk matched with the literature (Biswas et al., 2017; Krishna et al., 2015).

Whereas polypropylene was rich in carbon content (92 wt.\%), and $95 \mathrm{wt} . \%$ of the mass was expected to undergo conversion in pyrolysis. High amounts of elemental hydrogen and 
carbon significantly contributed to its high heating value $(45.7 \mathrm{MJ} / \mathrm{kg})$. Similar results were observed in polystyrene analysis; it was rich in carbon (91.4 wt.\%) and hydrogen (8.6 wt.\%) elements. The carbon content and heating value of plastics were relatively higher compared to the biomasses. The proximate and elemental data of polypropylene and polystyrene were wellmatched with the literature data (Bartoli et al., 2015; Suriapparao and Vinu, 2015).

\subsection{Analysis of Agro-residues Pyrolysis Products}

Individual pyrolysis of wheat straw (WS) and rice husk (RH) was conducted to investigate the role of pyrolysis parameters on the products. The product yields, bio-oil physicochemical properties, and char surface area are reported in Table 2. From the experimental code P1 and P2, it is obvious that $90 \mathrm{wt} . \%$ of WS was converted into oil and gas fractions at an average heating rate of $51{ }^{\circ} \mathrm{C} / \mathrm{min}$ and it took 8 minutes to reach the final pyrolysis temperature of $450^{\circ} \mathrm{C}$. The yield of gas (54 wt.\%) was quite higher compared to the oil fraction (35 wt.\%). On the other hand, in RH pyrolysis, the conversion was lower (70 wt.\%) due to the presence of high inorganic ash content. Hence, the yield of oil (29 wt.\%) and gases (41 wt.\%) fractions were lower as expected. The average heating rate achieved was a little higher $\left(56^{\circ} \mathrm{C} / \mathrm{min}\right)$ compared to WS case due to the presence of high ash content in the formed char. The specific microwave power (which is the ratio of microwave power to the mass of susceptor and feedstock) was constant $(6 \mathrm{~W} / \mathrm{g})$ in all the pyrolysis and co-pyrolysis experiments. However, due to the difference in the structure and origin of the feed material, microwave energy consumption is different. As shown in Fig 3, the microwave energy utilized in WS pyrolysis was calculated to be $\sim 2936 \mathrm{~J} / \mathrm{g}$ and that of rice husk is around $2679 \mathrm{~J} / \mathrm{g}$. It seems that the inherent char and ash presence in RH pyrolysis enhanced the heating rates, which eventually led to less energy consumption (Suriapparao et al., 2018). Of this, the generated heat energy in WS (1436 J/g) was 
a little higher compared to RH (1424 J/g). The heat energy used for the microwave pyrolysis obtained in this study was slightly lower than the conventional fluidized bed fast pyrolysis reported in the literature (1500 J/g) (Daugaard and Brown, 2003). Nevertheless, the increased processing time in wheat straw pyrolysis led to a bit of higher conductive heat loss $(110 \mathrm{~J} / \mathrm{g})$ compared to the rice husk $(100 \mathrm{~J} / \mathrm{g})$.

From the physicochemical analysis data reported in Table 2, it is quite obvious that the heating value for bio-oil increased to twofold when compared to raw biomasses. Interestingly, the heating value of $\mathrm{RH}$ bio-oil $(\sim 38 \mathrm{MJ} / \mathrm{kg})$ was relatively higher compared to WS oil ( $\sim 36$ $\mathrm{MJ} / \mathrm{kg}$ ) due to the ash catalytic activity of the former (Wan et al., 2009). The viscosity (24-25 $\mathrm{cP})$, density $\left(830-845 \mathrm{~kg} / \mathrm{m}^{3}\right)$, and flash point $\left(102-109^{\circ} \mathrm{C}\right)$ of bio-oil obtained from these two biomass feedstocks are in the same range. The obtained results are matching with the literature values (Suriapparao et al., 2018). The obtained char was rich in carbon content (60-70 wt.\%), and has a high heating value (15-32 MJ/kg). The heating value and carbon content of the WS char are higher compared to the RH char. The internal pore specific surface area $\left(110-115 \mathrm{~m}^{2} / \mathrm{g}\right)$ was relatively attractive. Further, char activation was needed to enhance its functionality and inner pores area.

From the bio-oil composition data depicted in Fig 4, it is quite clear that the bio-oil was a complex mixture containing aliphatic oxygenates (cyclic and straight-chain), aromatic oxygenates (phenol derivatives), aliphatic hydrocarbons (straight-chain and cyclic), aromatic hydrocarbons (mono and polyaromatics). The selectivity of the grouped compounds in the WS bio-oil is varied in the following order: aromatic hydrocarbons $(85.1 \%)>$ aromatic oxygenates $(8.4 \%)>$ alkanes $(2.9 \%)>$ aliphatic oxygenates $(2.5 \%)>$ cyclic alkanes and alkenes $(0.8 \%)$. So, it is pretty evident that most of the WS was converted into aromatics. On the other side, in RH 
bio-oil, we have noticed a different trend as follows: aromatic hydrocarbons $(37.8 \%)>$ cyclic alkanes and alkenes $(32.1 \%)>$ alkenes $(14.5 \%)>$ alkanes $(8.4 \%)>$ aromatic oxygenates $(2.3 \%)$. WS bio-oil contained high selectivity of ethylbenzene (73.2\%) and vinyl benzene $(5.7 \%)$. Whereas, RH bio-oil had three times lesser selectivity of ethylbenzene (21.8\%) compared to WS oil. So, from this analysis, it is evident that the cellulose and hemicellulose fractions were converted into gaseous products. Most of the lignin present in the WS and RH was converted into aromatic hydrocarbons.

From the carbon number distribution analysis shown in Fig 5, the carbon number distribution was observed to be in the range of C6 to C20. So, in microwave pyrolysis, longchain biopolymers (cellulose, hemicellulose, and lignin) were fragmented into smaller groups. WS bio-oil predominantly contained C8 carbon compounds (74\%) and trace amounts of other carbon number compounds also as observed. Carbon number ranging in between C8-C12 compounds (78.9\%) were noticed in RH bio-oil. Hence, in RH bio-oil a wide variety of spectrum of compounds was achieved. So the type of biomass feedstock played a vital role in the formation of pyrolysis products. If we observe the elemental $\mathrm{C}, \mathrm{H}$, and $\mathrm{O}$ analysis of WS and $\mathrm{RH}$ bio-oil depicted in Fig 6, the extent of de-oxygenation was superior, and it was reflected in the low oxygen content. The oxygen content of RH bio-oil $(0.8 \%)$ was twofold lesser compared to WS bio-oil (1.9\%). The hydrogen content was quite higher in the former $(12 \%)$ compared to the latter $(9.1 \%)$. The carbon recovery in both the bio-oils is in a similar range (87-89\%). So, most of the oxygen present in the WS and RH eventually transported into gaseous phases resulting in low oxygen content, high hydrocarbon selectivity, and thus bio-oils of high energy density were produced.

\subsection{Analysis of Waste Plastic Pyrolysis Products}


The pyrolysis studies conducted on the wheat straw and rice husk were extended to waste polypropylene and expanded polystyrene up-gradation as well. From the experimental codes P2 and P3 reported in Table 2, it is noted that 98.5 wt.\% of WPP was pyrolyzed into liquid and gaseous compounds. The yield of the gas (52 wt.\%) was higher compared to the liquid fraction (46 wt.\%). In the EPS pyrolysis, 99 wt.\% of conversion was obtained and the yield of liquid (78 wt.\%) was 3.7 times higher than that of the gas (21 wt.\%). The oil yield and the average heating rate obtained in EPS $\left(63^{\circ} \mathrm{C} / \mathrm{min}\right)$ was higher compared to $\mathrm{RH}\left(52^{\circ} \mathrm{C} / \mathrm{min}\right)$. It means that the cracking of EPS feedstock required less input energy and it could be processed at a faster rate comparatively. The microwave energy utilized in the pyrolysis of WPP $(2880 \mathrm{~J} / \mathrm{g})$ was higher compared to that of EPS (2520 J/g), as shown in Fig 3. Out of this input, microwave energy, $1443 \mathrm{~J} / \mathrm{g}$, and $1429 \mathrm{~J} / \mathrm{g}$ of heat energy utilized for WPP and EPS pyrolysis, respectively. Due to high processing time, the conductive heat losses in the pyrolysis of WPP (109 J/g) was higher compared to EPS $(95 \mathrm{~J} / \mathrm{g})$. The WPP char $\left(123 \mathrm{~m}^{2} / \mathrm{g}\right)$ had a higher specific surface area compared to the EPS char $\left(97 \mathrm{~m}^{2} / \mathrm{g}\right)$ due to the generation of high yield of lighter gases during the pyrolysis.

From the physicochemical analysis data of pyrolysis oil obtained from WPP and EPS raw materials, it is clear that WPP pyrolysis oil (46 MJ/kg) has a higher calorific value compared to the EPS pyrolysis oil (42 MJ/kg). Hence, both these oils have the potential to replace petroderived fuels due to their high heating density. However, WPP oil (125 cP) is more viscous compared to the EPS oil (1.5 cP). The density and flash point of EPS pyrolysis oil $\left(1098 \mathrm{~kg} / \mathrm{m}^{3}\right.$, $\left.96^{\circ} \mathrm{C}\right)$ was higher compared to WPP pyrolysis oil $\left(945 \mathrm{~kg} / \mathrm{m}^{3}, 81^{\circ} \mathrm{C}\right)$. It means that even though WPP pyrolysis oil was more viscous compared to the EPS pyrolysis oil, but its volatility was yet high. So, with the help of microwave pyrolysis and further up-gradation, it is possible to produce 
high-quality oils. The pore area analysis of char revealed that the WPP char $\left(123 \mathrm{~m}^{2} / \mathrm{g}\right)$, which is more porous compared to the EPS char $\left(97 \mathrm{~m}^{2} / \mathrm{g}\right)$. The formation of high yield of lighter gases was responsible for the better pore openings in the WPP char.

As depicted in the oil composition in Fig 4, almost 93.5\% of WPP pyrolysis had aliphatic hydrocarbons, along with $6.5 \%$ of aromatic hydrocarbons. The selectivity of hydrocarbons was varying in the following order: cycloalkanes and alkenes $(65.5 \%)>$ alkenes $(22.5 \%)>$ aromatics $(6.5 \%)>$ alkanes $(5.5 \%)$. Whereas, EPS oil is also contained high selectivity of cycloalkanes and alkenes $(65.8 \%)$ followed by aromatic hydrocarbons $(34.2 \%)$. So, it is clear that the formation of cyclic hydrocarbons was favored even though the plastic source was different. From the detailed analysis of the compounds, it was observed that EPS oil majorly contained $61 \%$ of $1,3,5,7-$ cyclooctatetraene and $14.4 \%$ of cyclopropyl methylbenzene. Both these compounds are the potential precursors in petrochemical industries. If we look into the WPP pyrolysis oil compound analysis, it predominantly contained $11.6 \%$ of 1,2,4-trimethyl cyclohexane, $9.6 \%$ of 1-ethyl-2propyl cyclohexane, $7.9 \%$ of 1,1,3,5-tetramethyl cyclohexane, 6.7\% of 1,2-diethyl-3-methyl cyclohexane, $6.3 \%$ of 2,4-diethyl-1-methylcyclohexane, and 5.1\% of 1,2-diethyl-1-methyl cyclohexane. Hence, it was evident that high selectivity of cyclic aliphatic hydrocarbons can be produced from WPP and EPS raw materials.

From the carbon number distribution analysis depicted in Fig 5, the majority of the hydrocarbons obtained in WPP pyrolysis have carbon number in the range of C9-C12 and varied in the following order: $\mathrm{C} 11(26.8 \%)>\mathrm{C} 10(20.5 \%)>\mathrm{C} 9(17 \%)>\mathrm{C} 12(14.2 \%)$. On another hand, EPS pyrolysis oil contained majorly C8 hydrocarbons (61.7\%) followed by C10 (14.2\%) and C14-C24 (9.7\%). The elemental data depicted in Fig 6. shows that the carbon content in EPS pyrolysis oil (92\%) was higher than that of WPP oil (86\%). Whereas, hydrogen content in the oil 
obtained from WPP $(13.9 \%)$ is higher compared to EPS $(7.9 \%)$. So, it infers that the saturation level in WPP pyrolysis oil was relatively high compared to the EPS pyrolysis oil.

\subsection{Co-Pyrolysis of Agro-residues with Waste Plastics}

Co-pyrolysis of agro-residues with waste plastics was conducted to investigate the effect of type of raw material and their mixing combinations on average heating rate, energy requirement, product yields, co-pyrolysis oil physicochemical properties, and composition. From the experimental codes C5, C6, C7, and C8 are reported in Table 2, and it is clear that the type of biomass, as well as the plastic, affected the conversion achieved in co-pyrolysis experiments. The average heating rate achieved to attain the final pyrolysis temperature $\left(450^{\circ} \mathrm{C}\right)$ was in the range of $63.4^{\circ} \mathrm{C} / \mathrm{min}$ to $66.7^{\circ} \mathrm{C} / \mathrm{min}$. Interestingly, the average heating rate obtained in copyrolysis experiments was higher compared to the individual pyrolysis of biomass and plastics. The presence of RH in RH:WPP and RH:EPS mixtures exhibited little higher heating rates compared to WS:WPP and WS:EPS mixtures. Similarly, The presence of EPS promoted higher heating rates in RH:EPS and WS:EPS mixtures compared to RH:WPP and WS:WPP mixtures. The conversion achieved in the co-pyrolysis was varying in the following order: WS:WPP $(92.2 \%)>$ WS:EPS $(91.6 \%)>$ RH:WPP $(89.9 \%)>$ RH:EPS $(89.1 \%)$. The yield of an oil fraction obtained is higher compared to the gas fraction in all the four co-pyrolysis experiments. The yield of oil is high with EPS in the feed mixture and it is varying in the following order: WS:EPS $(64.9 \%)>$ RH:EPS $(61.7 \%)>$ WS:WPP $(55.6 \%)>$ RH:WPP (51.5\%). From the energy analysis shown in Fig 3, it is clear that the amount of microwave energy, heat energy used and heat losses are lower compared to individual biomass and plastic pyrolysis. So, it is the indication that copyrolysis promoted the synergy between the biomass and plastics, and it eventually reduced the processing time and energy requirements. The microwave energy requirement in the co-pyrolysis 
was in the range of $2267 \mathrm{~J} / \mathrm{g}$ to $2385 \mathrm{~J} / \mathrm{g}$, on the other hand, in the individual pyrolysis, it is in the range of $2436 \mathrm{~J} / \mathrm{g}$ to $2936 \mathrm{~J} / \mathrm{g}$. The energy requirement with WPP in the mixture is high compared to EPS, and it was varying in the following order: WS:WPP $(2385 \mathrm{~J} / \mathrm{g})>\mathrm{RH}: \mathrm{WPP}$ $(2355 \mathrm{~J} / \mathrm{g})>$ WS:EPS $(2299 \mathrm{~J} / \mathrm{g})>$ RH:EPS $(2267 \mathrm{~J} / \mathrm{g})$. The heat energy used for the co-pyrolysis $1410 \mathrm{~J} / \mathrm{g}$ to $1420 \mathrm{~J} / \mathrm{g}$ and the conductive heat losses is in the range of $85 \mathrm{~J} / \mathrm{g}$ to $89 \mathrm{~J} / \mathrm{g}$.

From the physicochemical properties of co-pyrolysis oil reported in Table 2, the copyrolysis impact was not much noticed in the heating value. However, viscosity, density, and flashpoints were affected. The heating value was in the range of $40 \mathrm{MJ} / \mathrm{kg}$ to $41.7 \mathrm{MJ} / \mathrm{kg}$, which is closer to the petro-derived fuels. The viscosity of WS:WPP (75.7 cP) and RH:WPP (73.6 cP) co-pyrolysis oil are quite high compared to that of WS:EPS $(1.1 \mathrm{cP})$ and RH:EPS $(1.2 \mathrm{cP})$ oils. On the other side, WS:EPS $\left(954 \mathrm{~kg} / \mathrm{m}^{3}\right)$ and RH:EPS $\left(961 \mathrm{~kg} / \mathrm{m}^{3}\right)$ co-pyrolysis oils are denser compared to WS:WPP $\left(895 \mathrm{~kg} / \mathrm{m}^{3}\right)$ and RH:WPP $\left(878 \mathrm{~kg} / \mathrm{m}^{3}\right)$ oils due to the presence of a large number of high molecular mass compounds in the former. The presence of high volatile compounds in the WS:WPP $\left(82^{\circ} \mathrm{C}\right)$ and RH:WPP $\left(82^{\circ} \mathrm{C}\right)$ co-pyrolysis oils reduces their flash point compared to WS:EPS $\left(92^{\circ} \mathrm{C}\right)$ and RH:EPS $\left(89^{\circ} \mathrm{C}\right)$ oils. The surface area of char also varied with the nature of plastic added to the biomass. EPS promoted a high internal pore area compared to WPP. Hence, the char from WS:EPS $\left(123 \mathrm{~m}^{2} / \mathrm{g}\right)$ and RH:EPS $\left(126 \mathrm{~m}^{2} / \mathrm{g}\right)$ have a high pore area compared to WS:WPP $\left(105 \mathrm{~m}^{2} / \mathrm{g}\right)$ and RH:WPP $\left(101 \mathrm{~m}^{2} / \mathrm{g}\right)$ chars. Very interestingly, in the individual pyrolysis, EPS char was less porous compared to WPP. So, during the co-pyrolysis, the evolved vapors would have significantly altered the char pore area.

The carbon compound analysis shown in Fig 4, it was observed that aromatic hydrocarbons were the dominating group in all the four co-pyrolysis oils. The selectivity of aromatic hydrocarbons varied in the following order: WS:EPS $(93.6 \%)>$ RH:EPS $(90.7 \%)>$ 
RH:WPP (72.7\%) > WS:WPP (50.5\%). No cycloalkanes and alkenes compounds were observed in WS:EPS co-pyrolysis oil, whereas, $27 \%$ of the same category was noticed in WS:WPP copyrolysis oil. Hence, the co-pyrolysis synergy promoted benzene derivatives and cyclic aliphatic formation. From the detailed compound analysis, it was observed that RH:WPP co-pyrolysis contained high selectivity of 1,2,3-trimethyl benzene (17.7\%), O-xylene (7.5\%), ethylene benzene (6.2\%), ethylbenzene (5.8\%), naphthalene (4.7\%).Co-pyrolysis oil obtained from WS:WPP mixture majorly contained ethylene benzene (8.7\%), naphthalene (7.9\%), ethyl benzene (6\%), 1,3,5-trimethyl cyclohexane (5.2\%), 1-propenyl benzene (5.2\%). The RH:EPS copyrolysis oil predominantly contained vinyl benzene (27.3\%), methyl styrene (9.9\%), 2-phenyl naphthalene (7.7\%). Whereas, WS:EPS co-pyrolysis significantly composed of vinyl benzene $(28 \%)$, methyl styrene $(9.1 \%)$, stilbene $(5.3 \%)$, ethyl benzene $(5.2 \%)$. So, the formation of compounds solely depended upon the type of biomass and plastic used in the co-pyrolysis.

From the carbon number distribution analysis depicted in Fig 5, co-pyrolysis produced the carbon number in the range of C6-C24. WS:EPS co-pyrolysis oil contained compounds having a carbon number in the range of $\mathrm{C} 7$ to $\mathrm{C} 24$. In this range, $\mathrm{C} 8(31.5 \%), \mathrm{C} 15-\mathrm{C} 24(22.4 \%)$, and C9 (14.4\%) compounds were predominantly present. RH:EPS mixture also significantly produced C8 (29.6\%), C9 (15.2\%), C14 (8.6\%), and C15-C24 (29.8\%) carbon compounds. WS:WPP mixture dominantly promoted the formation of compounds with carbon number range of C8 (18.4\%), C9 (27.2\%), C10 (19.1\%), C11 (9\%), C12 (9.3\%). RH:WPP co-pyrolysis oil also majorly contained C8-C12 carbon compounds, and their selectivity varied in the following order: C9 $(23.2 \%)>\mathrm{C} 8(21.3 \%)>\mathrm{C} 10(12.7 \%)>\mathrm{C} 11(10.4 \%)>\mathrm{C} 12(5.5 \%)$. Hence, the formation of compounds and carbon number was greatly influenced by the type of biomass and plastic used in the co-pyrolysis. From the elemental composition analysis depicted in Fig 6, the elemental 
carbon in the co-pyrolysis oil was in the range of $88 \%$ to $92 \%$. It was varying in the following order: WS:EPS (92.4\%) > RH:EPS (91.9\%) > WS:WPP (88.6\%) RH:WPP (88.5\%). So, the presence of EPS enhanced the recovery of carbon in the oil fraction compared to WPP. The elemental hydrogen content is in the range of $7.2 \%$ to $10.5 \%$, and the highest hydrogen yield was observed with WPP in the mixtures WS:WPP (10.5\%) and RH:WPP(8.5\%) compared to the EPS in the mixture. The elemental oxygen content was very low $(0.3 \%$ to $2.9 \%)$ due to the high extent of de-oxygenation of oxygen present in the biomass into a gaseous fraction.EPS significantly suppressed the extent of oxygenated carbon compounds formation compared to WPP. Hence, the co-pyrolysis oil was rich with carbon and hydrogen contents, and hence energy density also increased.

\section{Conclusions}

The microwave energy (2267-2385 J/g), heat energy (1410-1421 J/g) requirements and conductive heat losses $(85-89 \mathrm{~J} / \mathrm{g})$ were lesser in co-pyrolysis compared to the individual pyrolysis. Bio-oil obtained from the rice husk contained aliphatic (54.9\%) and aromatic hydrocarbons $(37.8 \%)$, whereas wheat straw pyrolysis promoted a high yield of aromatic hydrocarbons $(85.1 \%)$ and aromatic oxygenates $(8.5 \%)$. The formation of the high selectivity of cyclic aliphatic hydrocarbons (65.5\%)was observed in polypropylene pyrolysis; on the other hand, polystyrene favored the formation of cyclic aliphatic $(65.8 \%)$ and aromatic $(34 \%)$ hydrocarbons.). The selectivity of aromatic hydrocarbons in co-pyrolysis oil was also suppressed by WPP (50-73\%) compared to EPS (91-94\%).

\section{Declaration of Competing Interest}

The authors declare that they have no known competing financial interest or personal relationships that could have appeared to influence the work reported in this manuscript. 


\section{Acknowledgments}

The corresponding author acknowledges the PanditDeendayal Petroleum University management for providing the faculty seed grant.

\section{References}

1.Abnisa, F., Wan Daud, W.M.A., 2014. A review on co-pyrolysis of biomass: An optional technique to obtain a high-grade pyrolysis oil. Energy Convers. Manag. 87, 71-85. https://doi.org/10.1016/j.enconman.2014.07.007

2.Alam, M., Bhavanam, A., Jana, A., Viroja, J. kumar S., Peela, N.R., 2020. Co-pyrolysis of bamboo sawdust and plastic: Synergistic effects and kinetics. Renew. Energy 149, 1133 1145. https://doi.org/10.1016/j.renene.2019.10.103

3.Anex, R.P., Aden, A., Kazi, F.K., Fortman, J., Swanson, R.M., Wright, M.M., Satrio, J.A., Brown, R.C., Daugaard, D.E., Platon, A., Kothandaraman, G., Hsu, D.D., Dutta, A., 2010. Techno-economic comparison of biomass-to-transportation fuels via pyrolysis, gasification, and biochemical pathways. Fuel 89, S29-S35. https://doi.org/10.1016/j.fuel.2010.07.015

4.Bartoli, M., Rosi, L., Frediani, M., Undri, A., Frediani, P., 2015. Depolymerization of polystyrene at reduced pressure through a microwave assisted pyrolysis. J. Anal. Appl. Pyrolysis 113, 281-287. https://doi.org/10.1016/j.jaap.2015.01.026

5.Beneroso, D., Bermúdez, J.M., Arenillas, A., Menéndez, J.A., 2014. Integrated microwave drying, pyrolysis and gasification for valorisation of organic wastes to syngas. Fuel. https://doi.org/10.1016/j.fuel.2014.04.064

6.Beneroso, D., Bermúdez, J.M., Arenillas, A., Menéndez, J.A., 2013. Microwave pyrolysis of microalgae for high syngas production. Bioresour. Technol. 144, 240-246. https://doi.org/10.1016/j.biortech.2013.06.102

7.Bhattacharya, M., Basak, T., 2017. Susceptor-Assisted Enhanced Microwave Processing of Ceramics - A Review. Crit. Rev. Solid State Mater. Sci. 42, 433-469. https://doi.org/10.1080/10408436.2016.1192987 
8.Biswas, B., Pandey, N., Bisht, Y., Singh, R., Kumar, J., Bhaskar, T., 2017. Bioresource Technology Pyrolysis of agricultural biomass residues : Comparative study of corn cob, wheat straw, rice straw and rice husk. Bioresour. Technol. 237, 57-63. https://doi.org/10.1016/j.biortech.2017.02.046

1. 9.Bu, Q., Chen, K., Xie, W., Liu, Y., Cao, M., Kong, X., Chu, Q., Mao, H., 2019. Hydrocarbon rich bio-oil production, thermal behavior analysis and kinetic study of microwave-assisted co-pyrolysis of microwave-torrefied lignin with low density polyethylene. Bioresour. Technol. 291, 121860. https://doi.org/10.1016/j.biortech.2019.121860

10.Bu, Q., Liu, Y., Liang, J., Morgan, H.M., Yan, L., Xu, F., Mao, H., 2018. Microwave-assisted co-pyrolysis of microwave torrefied biomass with waste plastics using ZSM-5 as a catalyst for high quality bio-oil. J. Anal. Appl. Pyrolysis 134, 536-543. https://doi.org/10.1016/j.jaap.2018.07.021

11.Chen, L., Yu, Z., Liang, J., Liao, Y., Ma, X., 2018. Co-pyrolysis of chlorella vulgaris and kitchen waste with different additives using TG-FTIR and Py-GC/MS. Energy Convers. Manag. 177, 582-591. https://doi.org/10.1016/j.enconman.2018.10.010

12.Chen, L., Yu, Z., Xu, H., Wan, K., Liao, Y., Ma, X., 2019. Microwave-assisted co-pyrolysis of Chlorella vulgaris and wood sawdust using different additives. Bioresour. Technol. 273, 34-39. https://doi.org/10.1016/j.biortech.2018.10.086

13.Dai, L., Zeng, Z., Yang, Q., Yang, S., Wang, Y., Liu, Y., Ruan, R., He, C., Yu, Z., Jiang, L., 2020. Synthesis of iron nanoparticles-based hydrochar catalyst for ex-situ catalytic microwave-assisted pyrolysis of lignocellulosic biomass to renewable phenols. Fuel 279, 118532. https://doi.org/10.1016/j.fuel.2020.118532

14.Daugaard, D.E., Brown, R.C., 2003. Enthalpy for pyrolysis for several types of biomass. Energy and Fuels 17, 934-939. https://doi.org/10.1021/ef020260x

15.Fan, H., Gu, J., Hu, S., Yuan, H., Chen, Y., 2019. Co-pyrolysis and co-gasification of biomass and polyethylene: Thermal behaviors, volatile products and characteristics of their residues. J. Energy Inst. 92, 1926-1935. https://doi.org/10.1016/j.joei.2018.11.002 
16.Ferrera-Lorenzo, N., Fuente, E., Bermúdez, J.M., Suárez-Ruiz, I., Ruiz, B., 2014.

Conventional and microwave pyrolysis of a macroalgae waste from the Agar-Agar industry. Prospects for bio-fuel production. Bioresour. Technol.

https://doi.org/10.1016/j.biortech.2013.10.047

17.Hiloidhari, M., Das, D., Baruah, D.C., 2014. Bioenergy potential from crop residue biomass in India. Renew. Sustain. Energy Rev. 32, 504-512.

https://doi.org/10.1016/j.rser.2014.01.025

18.Hu, Z., Zheng, Y., Yan, F., Xiao, B., Liu, S., 2013. Bio-oil production through pyrolysis of blue-green algae blooms (BGAB): Product distribution and bio-oil characterization. Energy. https://doi.org/10.1016/j.energy.2013.01.059

19.Johansson, A.C., Sandström, L., Öhrman, O.G.W., Jilvero, H., 2018. Co-pyrolysis of woody biomass and plastic waste in both analytical and pilot scale. J. Anal. Appl. Pyrolysis 134, 102-113. https://doi.org/10.1016/j.jaap.2018.05.015

20.Krishna, B.B., Singh, R., Bhaskar, T., 2015. Effect of catalyst contact on the pyrolysis of wheat straw and wheat husk. FUEL 160, 64-70. https://doi.org/10.1016/j.fuel.2015.07.065

21.Kumagai, S., Matsukami, A., Kabashima, F., Sakurai, M., Kanai, M., Kameda, T., Saito, Y., Yoshioka, T., 2020. Combining pyrolysis-two-dimensional gas chromatography-time-offlight mass spectrometry with hierarchical cluster analysis for rapid identification of pyrolytic interactions: Case study of co-pyrolysis of PVC and biomass components. Process Saf. Environ. Prot. 143, 91-100. https://doi.org/10.1016/j.psep.2020.06.036

22.Naqvi, S.R., Tariq, R., Hameed, Z., Ali, I., Naqvi, M., Chen, W.H., Ceylan, S., Rashid, H., Ahmad, J., Taqvi, S.A., Shahbaz, M., 2019. Pyrolysis of high ash sewage sludge: Kinetics and thermodynamic analysis using Coats-Redfern method. Renew. Energy 131, 854-860. https://doi.org/10.1016/j.renene.2018.07.094

23.Navarro, M. V., López, J.M., Veses, A., Callén, M.S., García, T., 2018. Kinetic study for the co-pyrolysis of lignocellulosic biomass and plastics using the distributed activation energy model. Energy 165, 731-742. https://doi.org/10.1016/j.energy.2018.09.133 
24.Önal, E., Uzun, B.B., Pütün, A.E., 2014. Bio-oil production via co-pyrolysis of almond shell as biomass and high density polyethylene. Energy Convers. Manag. 78, 704-710. https://doi.org/10.1016/j.enconman.2013.11.022

25.Oyedun, A.O., Tee, C.Z., Hanson, S., Hui, C.W., 2014. Thermogravimetric analysis of the pyrolysis characteristics and kinetics of plastics and biomass blends. Fuel Process. Technol. 128, 471-481. https://doi.org/10.1016/j.fuproc.2014.08.010

26.Özsin, G., Pütün, A.E., 2018. A comparative study on co-pyrolysis of lignocellulosic biomass with polyethylene terephthalate, polystyrene, and polyvinyl chloride: Synergistic effects and product characteristics. J. Clean. Prod. 205, 1127-1138. https://doi.org/10.1016/j.jclepro.2018.09.134

27.Park, K.-B., Jeong, Y.-S., Kim, J.-S., 2019. Activator-assisted pyrolysis of polypropylene. Appl. Energy 253, 113558. https://doi.org/10.1016/j.apenergy.2019.113558

28.Parvez, A.M., Afzal, M.T., Jiang, P., Wu, T., 2020. Microwave-assisted biomass pyrolysis polygeneration process using a scaled-up reactor: Product characterization, thermodynamic assessment and bio-hydrogen production. Biomass and Bioenergy 139, 105651. https://doi.org/10.1016/j.biombioe.2020.105651

29.Patil, V., Adhikari, S., Cross, P., 2018. Co-pyrolysis of lignin and plastics using red clay as catalyst in a micro-pyrolyzer. Bioresour. Technol. 270, 311-319. https://doi.org/10.1016/j.biortech.2018.09.034

30.Song, Z., Yang, Y., Sun, J., Zhao, X., Wang, W., Mao, Y., Ma, C., 2017. Effect of power level on the microwave pyrolysis of tire powder. Energy 127, 571-580. https://doi.org/10.1016/j.energy.2017.03.150

31.Suriapparao, D. V., Boruah, B., Raja, D., Vinu, R., 2018. Microwave assisted co-pyrolysis of biomasses with polypropylene and polystyrene for high quality bio-oil production. Fuel Process. Technol. 175, 64-75. https://doi.org/10.1016/j.fuproc.2018.02.019

32.Suriapparao, D. V., Vinu, R., 2015. Resource recovery from synthetic polymers via microwave pyrolysis using different susceptors. J. Anal. Appl. Pyrolysis 113, 701-712. 
https://doi.org/10.1016/j.jaap.2015.04.021

33.Suriapparao, D. V., Vinu, R., Shukla, A., Haldar, S., 2020. Effective deoxygenation for the production of liquid biofuels via microwave assisted co-pyrolysis of agro residues and waste plastics combined with catalytic upgradation. Bioresour. Technol. 302, 122775. https://doi.org/10.1016/j.biortech.2020.122775

34.Undri, A., Frediani, M., Rosi, L., Frediani, P., 2014. Reverse polymerization of waste polystyrene through microwave assisted pyrolysis. J. Anal. Appl. Pyrolysis 105, 35-42. https://doi.org/10.1016/j.jaap.2013.10.001

35.Uzoejinwa, B.B., He, X., Wang, S., El-Fatah Abomohra, A., Hu, Y., Wang, Q., 2018. Copyrolysis of biomass and waste plastics as a thermochemical conversion technology for high-grade biofuel production: Recent progress and future directions elsewhere worldwide. Energy Convers. Manag. 163, 468-492. https://doi.org/10.1016/j.enconman.2018.02.004

36.Wan, Y., Chen, P., Zhang, B., Yang, C., Liu, Y., Lin, X., Ruan, R., 2009. Journal of Analytical and Applied Pyrolysis Microwave-assisted pyrolysis of biomass : Catalysts to improve product selectivity 86, 161-167. https://doi.org/10.1016/j.jaap.2009.05.006

37.Xie, Q., Peng, P., Liu, S., Min, M., Cheng, Y., Wan, Y., Li, Y., Lin, X., Liu, Y., Chen, P., Ruan, R., 2014. Fast microwave-assisted catalytic pyrolysis of sewage sludge for bio-oil production. Bioresour. Technol. 172, 162-168.

https://doi.org/10.1016/j.biortech.2014.09.006

38.Xue, Y., Bai, X., 2018. Synergistic enhancement of product quality through fast co-pyrolysis of acid pretreated biomass and waste plastic. Energy Convers. Manag. 164, 629-638. https://doi.org/10.1016/j.enconman.2018.03.036

39.Yu, Y., Yu, J., Sun, B., Yan, Z., 2014. Influence of catalyst types on the microwave-induced pyrolysis of sewage sludge. J. Anal. Appl. Pyrolysis 106, 86-91. https://doi.org/10.1016/j.jaap.2014.01.003

40.Zheng, Y., Tao, L., Yang, X., Huang, Y., Liu, C., Zheng, Z., 2018. Study of the thermal behavior, kinetics, and product characterization of biomass and low-density polyethylene 
co-pyrolysis by thermogravimetric analysis and pyrolysis-GC/MS. J. Anal. Appl. Pyrolysis 133, 185-197. https://doi.org/10.1016/j.jaap.2018.04.001

41.Zhou, N., Zhou, J., Dai, L., Guo, F., Wang, Y., Li, H., Deng, W., Lei, H., Chen, P., Liu, Y., Ruan, R., 2020. Syngas production from biomass pyrolysis in a continuous microwave assisted pyrolysis system. Bioresour. Technol. 314, 123756.

https://doi.org/10.1016/j.biortech.2020.123756 
Table 1. The Proximate, elemental and heating valueanalysis of Raw materials.

\begin{tabular}{|c|c|c|c|c|c|c|c|c|c|}
\hline \multirow{2}{*}{ Raw material } & \multicolumn{3}{|c|}{ Proximate analysis (wt.\%) } & \multicolumn{4}{|c|}{ Elemental analysis (wt.\%) } & \multirow{2}{*}{$\mathrm{O}^{\mathrm{a}}$} & \multirow{2}{*}{$\begin{array}{c}\mathrm{HHV} \\
(\mathrm{MJ} / \mathrm{kg})\end{array}$} \\
\hline & VM & $\mathrm{FC}$ & Ash & $\mathrm{C}$ & $\mathrm{H}$ & $\mathrm{N}$ & $\mathrm{S}$ & & \\
\hline Graphite & 1.0 & 97.5 & 1.5 & 98 & 0.0 & 0.0 & 0.0 & - & 32.2 \\
\hline Wheat Straw & 80.7 & 10.5 & 8.8 & 42.5 & 5.5 & 1.1 & 0.1 & 50.8 & 17.5 \\
\hline Rice Husk & 63.1 & 12.4 & 24.5 & 41.1 & 5.0 & 0.4 & 0.3 & 53.2 & 14.5 \\
\hline Waste Polypropylene & 95.0 & 4.5 & 0.5 & 92.5 & 7.5 & 0.0 & 0.0 & - & 45.7 \\
\hline $\begin{array}{l}\text { Expanded } \\
\text { Polystyrene }\end{array}$ & 98.9 & 0.6 & 0.5 & 91.4 & 8.6 & 0.0 & 0.0 & - & 41.6 \\
\hline
\end{tabular}

${ }^{\mathrm{a} B y}$ difference: $\mathrm{O}=100-\mathrm{C}-\mathrm{H}-\mathrm{N}-\mathrm{S}, \mathrm{VM}-$ Volatile matter, FC-Fixed carbon. 
Table 2. Average heating rate, product yields, oil physicochemical properties and char surface area obtained in pyrolysis and co-pyrolysis experiments.

\begin{tabular}{|c|c|c|c|c|c|c|c|c|c|c|}
\hline \multirow{2}{*}{$\begin{array}{l}\text { Expt. } \\
\text { code }\end{array}$} & \multirow{2}{*}{$\begin{array}{c}\text { Raw } \\
\text { material }\end{array}$} & \multirow{2}{*}{$\begin{array}{l}\text { Avg. } \\
\text { Heating } \\
\text { rate } \\
\left({ }^{\circ} \mathrm{C} / \mathrm{min}\right) \\
\end{array}$} & \multicolumn{3}{|c|}{ Product yield (wt.\%) } & \multicolumn{4}{|c|}{ Oil } & \multirow{2}{*}{$\begin{array}{c}\text { Char } \\
\text { surface } \\
\text { area }\left(\mathrm{m}^{2} / \mathrm{g}\right.\end{array}$} \\
\hline & & & Char & Gas & Oil & $\begin{array}{c}\mathrm{HHV} \\
(\mathrm{MJ} / \mathrm{kg})\end{array}$ & $\begin{array}{c}\text { Viscosity } \\
\text { (cP) }\end{array}$ & $\begin{array}{l}\text { Density } \\
\left(\mathrm{kg} / \mathrm{m}^{3}\right)\end{array}$ & $\begin{array}{c}\text { Flashpoint } \\
\left({ }^{\circ} \mathrm{C}\right)\end{array}$ & \\
\hline $\mathrm{P} 1$ & WS & 51.5 & $10.2 \pm 0.1$ & $54.4 \pm 0.1$ & $35.4 \pm 0.1$ & 35.5 & 25.2 & 831 & 109.5 & 110 \\
\hline $\mathrm{P} 2$ & RH & 56.3 & $30.1 \pm 0.1$ & $41.2 \pm 0.1$ & $28.7 \pm 0.1$ & 37.7 & 23.9 & 845 & 101.8 & 115 \\
\hline P3 & WPP & 52.4 & $1.5 \pm 0.1$ & $52.2 \pm 0.1$ & $46.3 \pm 0.1$ & 45.9 & 124.8 & 945 & 81.1 & 123 \\
\hline P4 & EPS & 62.5 & $1.0 \pm 0.1$ & $20.8 \pm 0.1$ & $78.2 \pm 0.1$ & 42.4 & 1.5 & 1098 & 95.7 & 97 \\
\hline $\mathrm{C} 5$ & WS:WP & 63.4 & $7.8 \pm 0.1$ & $36.6 \pm 0.1$ & $55.6 \pm 0.1$ & 41.5 & 75.7 & 895 & 82.3 & 105 \\
\hline $\mathrm{C} 6$ & WS:EPS & 65.6 & $8.4 \pm 0.1$ & $26.7 \pm 0.1$ & $64.9 \pm 0.1$ & 41.6 & 1.1 & 954 & 91.9 & 123 \\
\hline $\mathrm{C} 7$ & RH:WPP & 64.5 & $10.1 \pm 0.1$ & $38.4 \pm 0.1$ & $51.5 \pm 0.1$ & 40.1 & 73.6 & 878 & 81.8 & 101 \\
\hline $\mathrm{C} 8$ & RH:EPS & 66.7 & $10.9 \pm 0.1$ & $27.4 \pm 0.1$ & $61.7 \pm 0.1$ & 41.7 & 1.2 & 961 & 89.5 & 126 \\
\hline
\end{tabular}


Fig 1. The schematic of the experimental setup.

Fig 2. The new approach is used in the susceptor and feedstock blending.

Fig 3. The microwave energy utilized, heat energy generated, and conductive heat losses in pyrolysis and co-pyrolysis experiments.

Fig 4. Composition of carbon compounds present in the pyrolysis and co-pyrolysis oils.

Fig 5. Pyrolysis and co-pyrolysis oils carbon distribution comparison analysis.

Fig 6. Comparison of elemental analysis of pyrolysis and co-pyrolysis oils with the raw materials. 


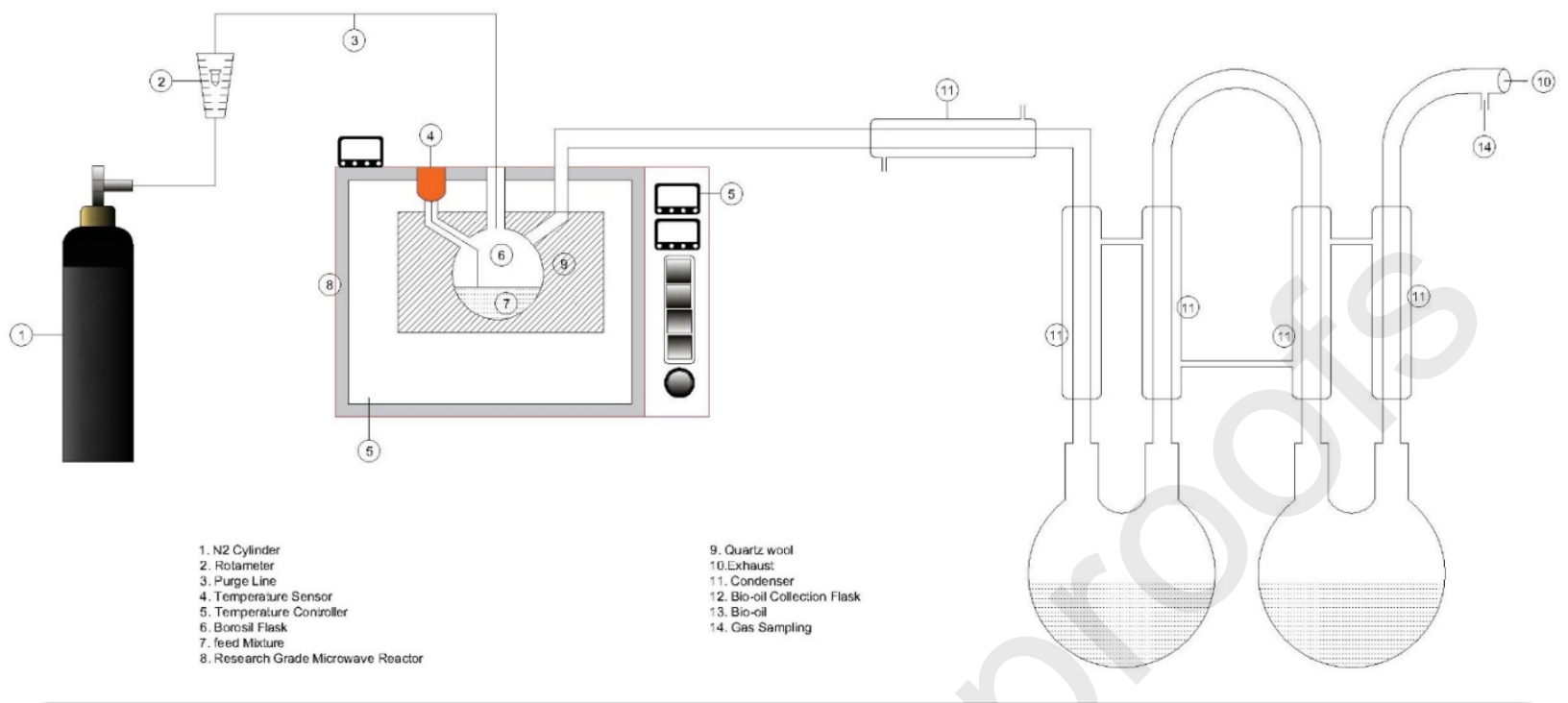

Fig 1. The schematic of the experimental setup. 


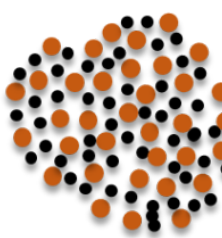

Physical blending

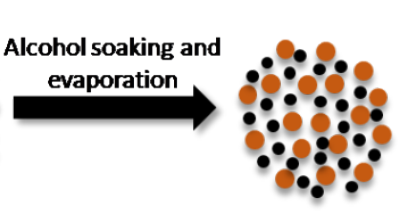

Alcohol blending

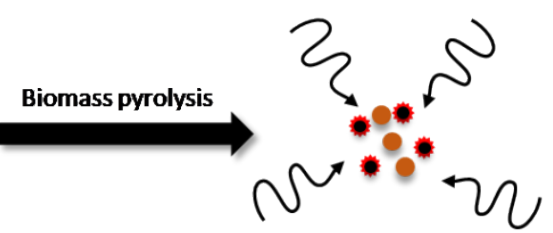

Microwave heating mechanism

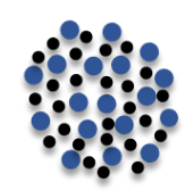

Physical blending

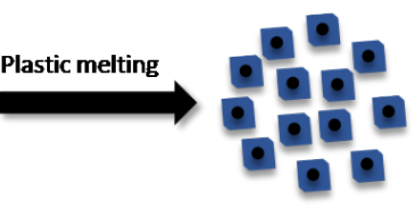

Melt phase blending

\section{Plastic pyrolysis}

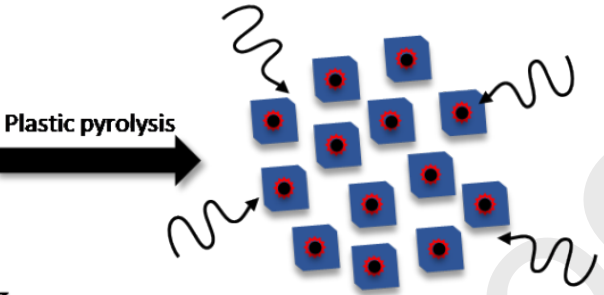

Microwave heating mechanism

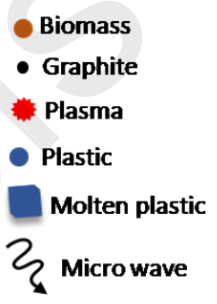

Biomass

- Graphite

- Plasma

- Plastic

2 Micro wave

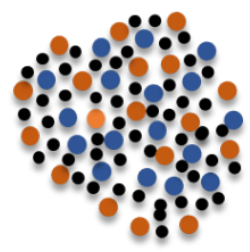

Physical blending

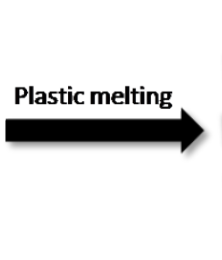

Melt phase blending

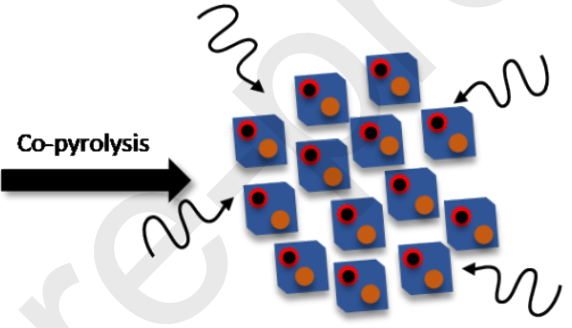

Microwave heating mechanism

Fig 2. The new approach is used in the susceptor and feedstock blending. 

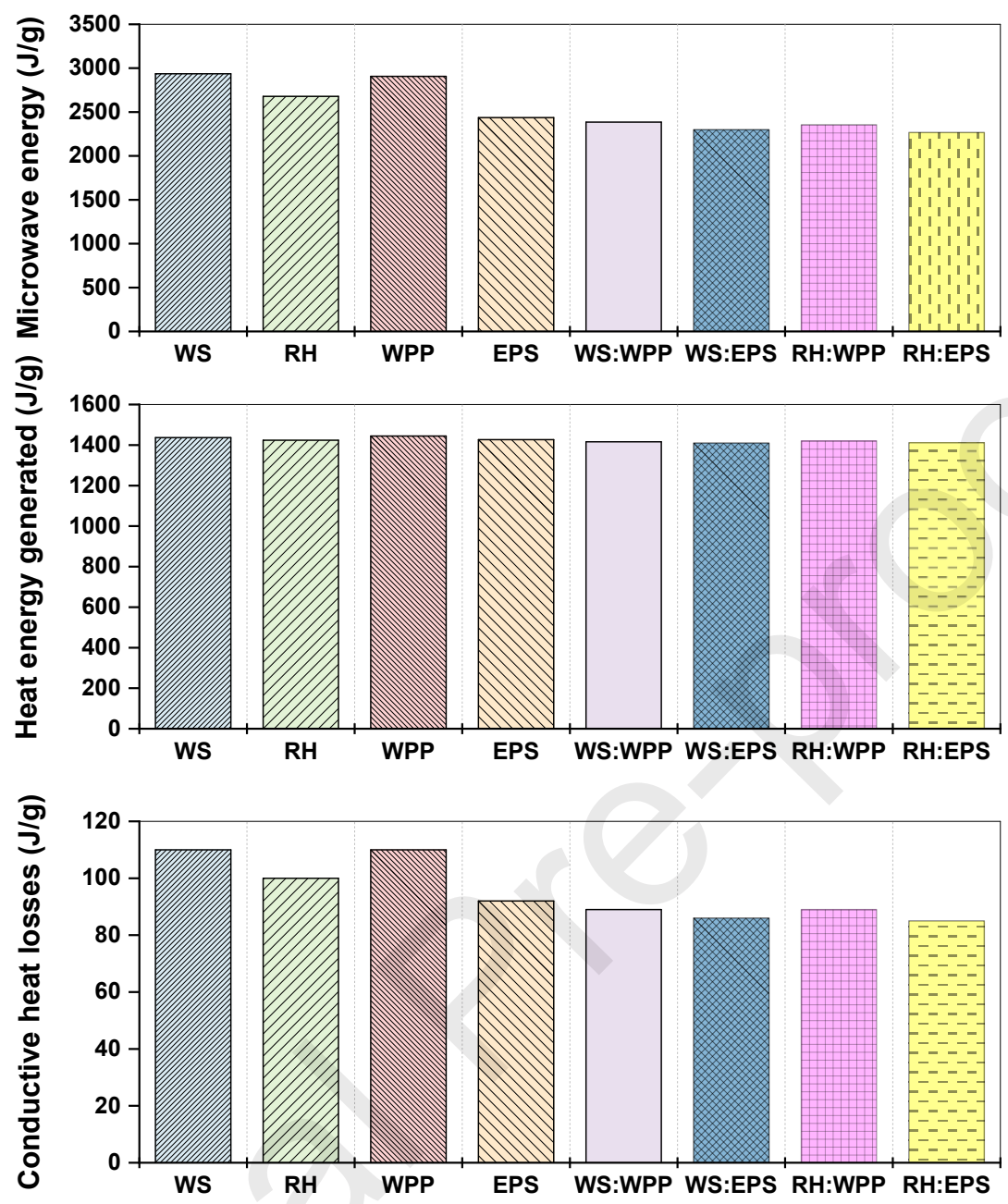

Fig 3. The microwave energy utilized, heat energy generated, and conductive heat losses in pyrolysis and co-pyrolysis experiments. 


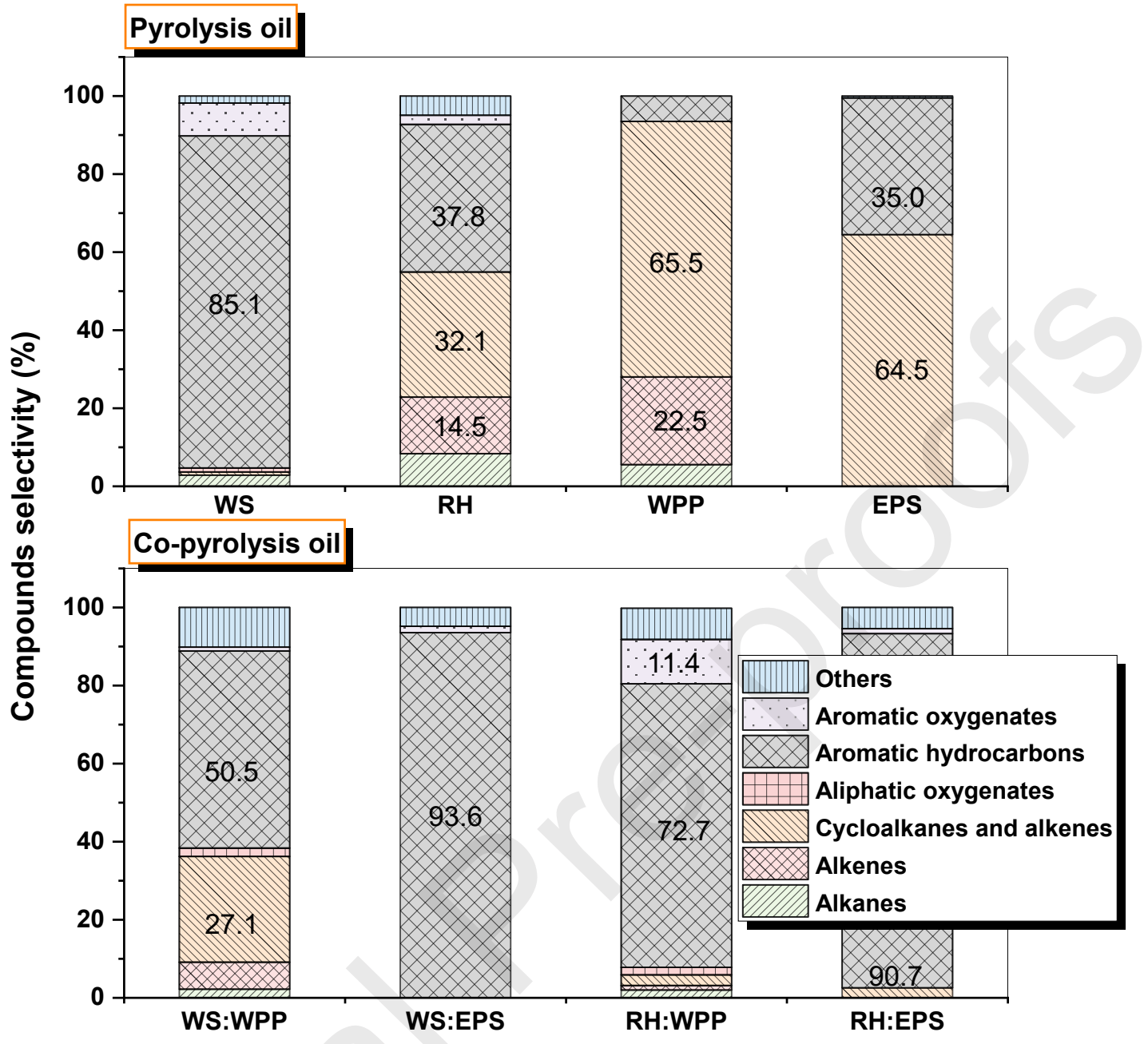

Fig 4. Composition of carbon compounds present in the pyrolysis and co-pyrolysis oils. 


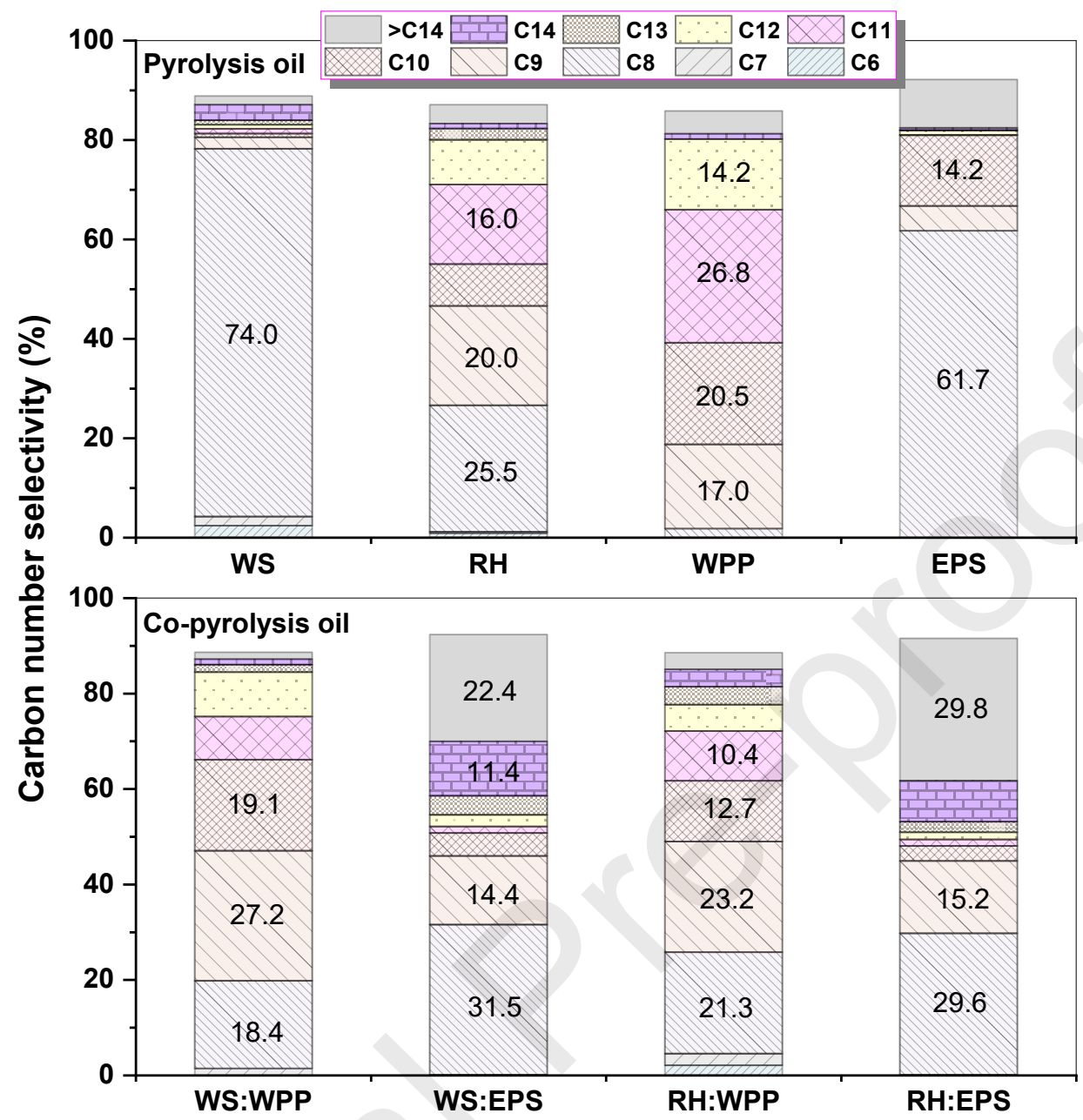

Fig 5. Pyrolysis and co-pyrolysis oils carbon distribution comparison analysis. 

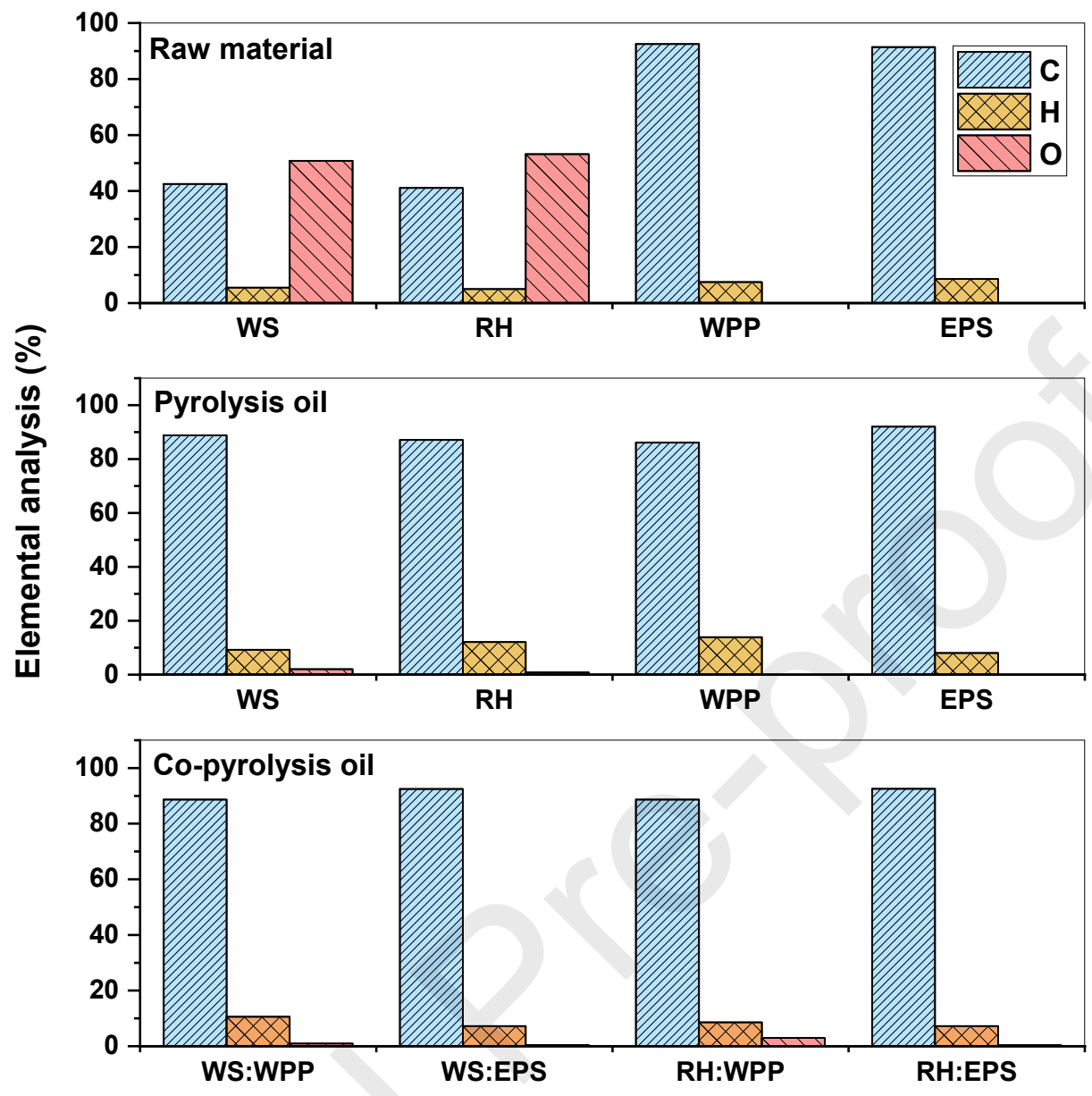

Fig 6. Comparison of elemental analysis of pyrolysis and co-pyrolysis oils with the raw materials.

\title{
CRediT author statement
}

\author{
Dadi V. Suriapparao \\ Conceptualization, Data Curation, Investigation, \\ Writing-Original Draft, Supervision
}


Draft

\begin{tabular}{ll}
\hline Garlapati Nagababu & Software, Data Curation, Writing- Review \\
& \&Editing
\end{tabular}

Ramesh K. Guduru Validation, Writing- Review \&Editing

Tanneru Hemanth Kumar $\quad$ Resources, Writing-Original Draft

\section{Graphical Abstract}

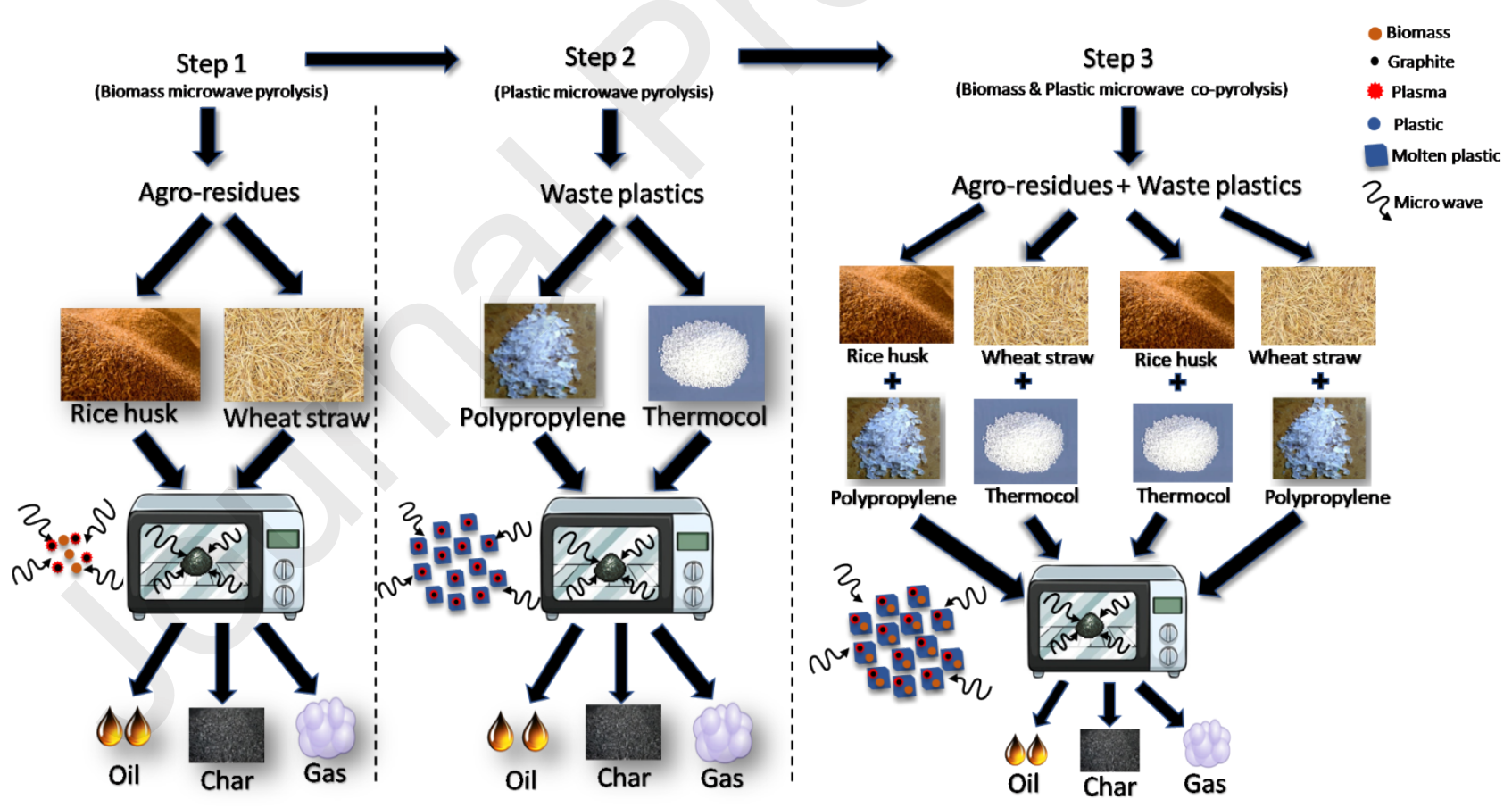

\section{Highlights}


1. A new concept in susceptor and feedstock homogenous blending was conducted

2. Energy requirements of pyrolysis and co-pyrolysis were comparatively analysed

3. Low bulk heating rates resulted in fast/flash Pyrolysis and co-pyrolysis product yields

4. Biomass pyrolysis promoted cyclic aliphatic hydrocarbons and aromatic hydrocarbons

5. Plastic pyrolysis favoured cyclohexane (WPP) and cyclooctatetraene (EPS) compounds

\section{Conflict of Interest and Authorship Confirmation Form}

Please check the following as appropriate:

- All authors have participated in (a) conception and design, or analysis and interpretation of the data; (b) drafting the article or revising it critically for important intellectual content; and (c) approval of the final version.

- This manuscript has not been submitted to, nor is under review at, another journal or other publishing venue.

- The authors have no affiliation with any organization with a direct or indirect financial interest in the subject matter discussed in the manuscript

- The following authors have affiliations with organizations with a direct or indirect financial interest in the subject matter discussed in the manuscript: 
Dadi V. Suriapparao

Attada Yerrayya

Garlapati Nagababu

Ramesh K. Guduru

Tanneru Hemanth Kumar
Department of Chemical Engineering, Pandit Deendayal Petroleum University, Gandhinagar-382007, India

KAUST Catalysis Center (KCC), King Abdullah University of Science and Technology, Thuwal 23955-6900, Saudi Arabia

Department of Mechanical Engineering, Pandit Deendayal Petroleum University, Gandhinagar-382007, India

Department of Mechanical Engineering, Pandit Deendayal Petroleum University, Gandhinagar-382007, India

Department of Chemical Engineering, Indian Institute of petroleum Energy, Visakhapatnam-530003, India 